\title{
Balkanologie
}

Balkanologie Revue d'études pluridisciplinaires

Vol. III, n² | 1999

Volume III Numéro 2

\section{Hartmann(Florence), Milosevic : la diagonale du fou}

Paris : Denoël, 1999, 441 p.

Yves Tomić

\section{CpenEdition}

\section{Journals}

Édition électronique

URL : http://journals.openedition.org/balkanologie/2197

DOI : 10.4000/balkanologie.2197

ISSN : 1965-0582

\section{Éditeur}

Association française d'études sur les Balkans (Afebalk)

Édition imprimée

Date de publication : 1 décembre 1999

ISSN : 1279-7952

\section{Référence électronique}

Yves Tomić, «Hartmann(Florence), Milosevic : la diagonale du fou », Balkanologie [En ligne], Vol. III, n² | 1999, mis en ligne le 22 juin 2010, consulté le 17 décembre 2020. URL : http://

journals.openedition.org/balkanologie/2197 ; DOI : https://doi.org/10.4000/balkanologie.2197

Ce document a été généré automatiquement le 17 décembre 2020.

(c) Tous droits réservés 


\section{Hartmann(Florence), Milosevic : la diagonale $\mathrm{du}$ fou}

Paris : Denoël, 1999, 441 p.

Yves Tomić

\section{RÉFÉRENCE}

Hartmann (Florence), Milosevic : la diagonale du fou, Paris : Denoël, 1999, 441 p.

1 Ce livre consacré à Slobodan Milošević est le premier du genre publié en France. L'actuel président yougoslave qui domine la vie politique de la Serbie depuis 1987 n'avait pas encore fait l'objet d'études plus approfondies en France, hormis dans le cadre de quelques articles publiés dans diverses revues. L'auteur, journaliste, connaît bien son sujet : Florence Hartmann a été correspondante du Monde pendant plusieurs années à Belgrade, elle connaît le serbo-croate et a donc eu accès à des sources locales (ouvrages, témoignages).

2 L'ouvrage retrace rapidement l'ascension politique de Slobodan Milošević au cours des années 1980. L'auteur fait ensuite le récit de la désintégration de la Yougoslavie et de l'éclatement des conflits armés en Slovénie, en Croatie et en Bosnie-Herzégovine soulignant à chaque fois le rôle et l'implication de Slobodan Milošević dans ces événements tragiques. Un reproche que l'on peut d'ailleurs adresser à l'auteur est qu'il suit le parcours de Slobodan Milošević uniquement à travers le prisme des guerres : il ne présentent pas suffisamment les évolutions politiques internes en Serbie, le système de gouvernement du président serbe, etc. Il n'explique pas suffisamment comment Slobodan Milošević a pu se maintenir au pouvoir si longtemps malgré les résultats désastreux de sa politique. En effet, plus qu'une biographie politique de Slobodan Milošević, il s'agit d'un récit sur les différents conflits armés qui se sont succédés dans l'espace yougoslave depuis 1990. Florence Hartmann décrit d'ailleurs très bien la machine de guerre instaurée par $\mathrm{S}$. Milošević, notamment le rôle assigné au ministère de l'Intérieur de Serbie, aux services secrets et aux milices constituant son "armée 
parallèle". Son récit relie les événements isolés, les met en perspective et contribue à une meilleure compréhension de l'entreprise militaire menée par S. Milošević à Belgrade. L'auteur montre clairement que le dirigeant de Belgrade n'était pas intéressé par les Serbes de Croatie et leurs territoires : son principal objectif était la séparation des peuples serbe et croate et surtout le dépeçage de la Bosnie-Herzégovine au profit de la Serbie et de la Croatie. Les Serbes de Croatie n'étaient qu'une monnaie d'échange dans le cadre du partage de la Bosnie-Herzégovine. Le chapitre sur «l'abandon de la Krajina » par la Serbie est à ce propos éloquent.

À plusieurs endroits de l'ouvrage, l'historien reste sur sa faim. En effet, des affirmations sont avancées sans qu'elles soient étayées de sources précises : par exemple, Florence Hartmann attribue un rôle moteur à Dobrica ćosić en évoquant les manifestations de 1988-1989. S'il est indéniable que le romancier serbe un joué un rôle primordial dans le réveil national, peut-on affirmer qu'il a orchestré la «croisade nationale à travers la Serbie » à cette époque (p. 38) ou que le Mémorandum de l'Académie serbe des sciences et des arts a été rédigé « sous ses ordres " (p. 393) ? De même lorsque l'auteur évoque (p. 256) les services de renseignement yougoslaves chargés d'évaluer la détermination de l'OTAN à intervenir ou encore le plan RAM visant à conquérir la Bosnie-Herzégovine (p. 264), des sources s'imposaient pour renforcer la crédibilité du récit. Ce n'est pas que l'auteur ne cite pas de sources, mais étant donné l'importance du sujet et les nombreuses polémiques qui ont eu cours sur les événements en question un appareil de notes plus riche aurait été appréciable. Une carte de l'ex-Yougoslavie ou au moins de la Croatie et de la Bosnie-Herzégovine permettrait une lecture plus facile de l'ouvrage par les non-spécialistes de la question.

4 Certaines affirmations sont contestables: dire que le nationalisme serbe de la fin des années 1980 a généré le nationalisme croate et a conduit Franjo Tuđman au pouvoir à Zagreb (p. 87), c'est oublier que le nationalisme croate s'était déjà manifesté en Croatie, surtout entre 1967 et 1971, et que ce mouvement nationaliste avait été réprimé par le régime communiste titiste à partir de 1971. Indépendamment de la situation en Serbie, les acteurs du mouvement national croate avaient une revanche à prendre sur les communistes : sans Milošević, ils auraient pris place sur la scène politique croate.

Ces quelques remarques n'enlèvent rien à la qualité de l'ouvrage en question qui est certainement l'un des meilleurs parus en France sur la désintégration de la Yougoslavie et les guerres qui ont ravagé la Croatie, la Bosnie-Herzégovine et le Kosovo, notamment grâce à l'utilisation de sources précieuses en serbo-croate.

\section{AUTEURS}

YVES TOMIĆ 